\title{
Growth of uncultured heterotrophic flagellates in unamended seawater incubations
}

\author{
Ramon Massana $^{1, *}$, Laure Guillou ${ }^{2}$, Ramon Terrado ${ }^{1,3}$, Irene Forn ${ }^{1}$, Carlos Pedrós-Alió ${ }^{1}$ \\ ${ }^{1}$ Institut de Ciències del Mar, CMIMA (CSIC), Passeig Marítim de la Barceloneta 37-49, 08003 Barcelona, Catalonia, Spain \\ ${ }^{2}$ Station Biologique de Roscoff, UMR 7127 (CNRS et Université Pierre et Marie Curie), BP 74, 29682 Roscoff, France \\ ${ }^{3}$ Départment de Biologie, Université Laval, Québec City, Québec G1K 7P4, Canada
}

\begin{abstract}
Unamended dark incubations of $3 \mu \mathrm{m}$-filtered seawater were prepared with surface samples from the Norwegian Sea, the NW Mediterranean and the Indian Ocean. Except for the very oligotrophic Indian Ocean samples, this simple treatment promoted the growth of heterotrophic flagellates, with rates $\left(0.3\right.$ to $\left.1.2 \mathrm{~d}^{-1}\right)$ typical of natural assemblages. Marine stramenopile (MAST)-1 and MAST-4 cell counts, obtained by fluorescence in situ hybridization (FISH), increased in most incubations. These yet uncultured protists were first detected in molecular surveys of marine picoplankton and have been recently shown to be globally distributed heterotrophic flagellates. Three incubations from the Norwegian Sea were studied in more detail by denaturing gradient gel electrophoresis (DGGE), 18S rRNA gene clone libraries and FISH counts for 5 MAST groups. Protist diversity changed gradually during the incubation, but the DGGE bands selected were already present at the beginning of the incubation. Clone libraries from the peaks in abundance of heterotrophic flagellates were dominated by MAST sequences. FISH counts revealed MAST-1B to be a very successful organism in the 3 incubations, accounting for 15 to $30 \%$ of heterotrophic flagellates after 6 to $8 \mathrm{~d}$ i MAST-1A and -1C cells were also abundant. MAST-4 cells peaked before the other groups and MAST-2 was the least represented. We concluded that unamended seawater incubations can select for heterotrophic flagellates abundant in situ but not yet isolated in pure culture. Therefore, they allow investigation of the growth requirements and dynamics of these uncultured protists, and provide promising preliminary stages for their isolation.
\end{abstract}

KEY WORDS: Heterotrophic flagellates - Unamended incubations · MAST $\cdot$ Uncultured protists · FISH $\cdot$ DGGE

\section{INTRODUCTION}

Conceptual models of carbon flow in marine planktonic food webs changed drastically with the realization of the importance of heterotrophic bacteria growing on dissolved organic matter (Pomeroy 1974). In this new paradigm, bacteria were consumed by small predators, loosely referred to as heterotrophic flagellates (Fenchel 1986), which linked bacteria with higher trophic levels in the so-called microbial loop (Azam et al. 1983). This view was complicated by the discovery of multiple trophic levels within heterotrophic flagellates (Wikner \& Hagström 1988), of their ability to graze on picophytoplankton (Caron et al. 1991), and of viruses as additional players in bacterial mortality
(Proctor \& Fuhrman 1990). Although the significance of heterotrophic flagellates in carbon transfer is still debated, it is widely accepted that they exert strong grazing pressure on picoplankton populations and are central in nutrient recycling (Sherr \& Sherr 2002, Pernthaler 2005). Given this central importance and considering that different species surely imply functional differences in terms of food spectra, prey-predator interactions, and biogeochemical cycling (Boenigk \& Arndt 2002), it is surprising how little we know about the diversity of in situ marine heterotrophic flagellates (Arndt et al. 2000).

Heterotrophic flagellates are routinely quantified by epifluorescence microscopy after DAPI staining (Porter \& Feig 1980). In marine systems, cells smaller than 
$5 \mu \mathrm{m}$ in diameter dominate in numbers (Sherr et al. 1997, Caron et al. 1999, Jürgens et al. 2000), but these remain mostly unidentified in terms of phylogenetic affiliation owing to the few observable morphological features. The long list of formally described marine species (Lee \& Patterson 1998) derives mainly from cultures or enrichments started by adding a substrate for bacterial growth that, in turn, are the food for the flagellates. While it is obvious that these easily enriched strains live in the sea, it is doubtful that they are dominant members of natural assemblages. A now classic study demonstrated that the heterotrophic flagellate dominating several enrichments was rare in the original samples (Lim et al. 1999). On the other hand, recent molecular surveys of surface marine picoplankton (Díez et al. 2001a, Moon-van der Staay et al. 2001) retrieved very few sequences related to known heterotrophic flagellates. Instead, these surveys revealed a large number of uncultured lineages, such as the marine stramenopiles (MAST) that formed up to 12 independent lineages (Massana et al. 2004). It has recently been shown that some of these MAST lineages are heterotrophic flagellates with a global distribution and significant abundance in the oceans (Massana et al. 2006). It is thus clear that culture isolations and molecular surveys are providing different views on the species composition of marine heterotrophic flagellates.

Unamended seawater incubations with size-fractionated microbial assemblages can establish a bridge between both approaches. By incubating $3 \mu \mathrm{m}$-filtered seawater in the dark, bacteria growing on autochthonous substrates allow for a moderate pulse of heterotrophic flagellates, which can then be identified by molecular tools. Although short-lived, these events can provide interesting information on marine protists, especially if growth of uncultured organisms is promoted. In an incubation performed on a sample from Blanes Bay (NW Mediterranean), we observed growth of MAST-3 and MAST-4 cells and demonstrated that they were heterotrophic flagellates (Massana et al. 2002). This study provided useful phenotypic and functional information on uncultured protists and showed the potential of this approximation, but it remained to be known whether it represented a peculiarity of the sample analyzed or an example of a more general phenomenon.

We conducted unamended seawater incubations in 3 oceanographic areas: the Blanes Bay Microbial Observatory (5 times throughout the year), the Norwegian Sea (at 1 coastal and 2 offshore stations) and the Indian Ocean (at 5 stations along a transect from South Africa to Australia). The growth of MAST cells was checked by fluorescence in situ hybridization (FISH) at the beginning and at the time of maximal abundance of heterotrophic flagellates. In addition, the 3 incubations from the Norwegian Sea were studied in more detail. This is a complex oceanographic region where Atlantic and Arctic waters meet, and data on abundance and community structure of picoeukaryotes from the same cruise were presented elsewhere (Not et al. 2005, Lovejoy et al. 2006). Population dynamics of protists was followed by denaturing gradient gel electrophoresis (DGGE), and the major populations of heterotrophic flagellates growing were identified in 18S rRNA gene clone libraries. Since MAST lineages were well represented in clone libraries, we followed the dynamics of these cells by FISH.

\section{MATERIALS AND METHODS}

Sampling. Water samples from the Blanes Bay Microbial Observatory (NW Mediterranean Sea) were retrieved $800 \mathrm{~m}$ offshore at 5 different times of the year, including fall, winter and summer. Water samples from the Norwegian Sea and the Indian Ocean were collected with Niskin bottles attached to a CTD rosette on cruises with RV 'Johan Hjort' (Norwegian Institute of Marine Research) and RV 'Melville' (Scripps Institution of Oceanography), respectively. Three stations were sampled in the Norwegian Sea: near the coast (Coastal), southeast of Spitzbergen with Barents Sea influence (Polar), and southwest of the island (Atlantic). Five stations were sampled in the Indian Ocean between the African coast and Keeling Island. Station locations, date of sampling and temperature and chlorophyll a (chl a) concentration of surface samples used for incubations are shown in Table 1.

Unamended seawater incubations. Surface seawater was filtered by gravity first through a nylon mesh of $200 \mu \mathrm{m}$ and later through polycarbonate filters (Poretics) of $3 \mu \mathrm{m}$ pore size (except for the first Blanes sample, which was filtered through $2 \mu \mathrm{m}$ ). Subsequently, 21 of the filtered seawater were dispensed into Nalgene polycarbonate bottles and incubated in the dark at near in situ temperature (in a laboratory chamber for Blanes or inside a tank with running surface seawater for the 2 cruises). Mean temperature for the incubations in the Norwegian Sea and the Indian Ocean was 9 and $24^{\circ} \mathrm{C}$, respectively. Bottles were sampled every 1 to $2 \mathrm{~d}$. Subsamples for epifluorescence microscopy were fixed with ice-cold glutaraldehyde ( $1 \%$ final concentration), stained with DAPI and filtered onto 0.2 or $0.6 \mu \mathrm{m}$ pore-size black polycarbonate filters (Poretics) for numeration of bacteria (but potentially also including Archaea and Prochlorococcus), Synechococcus, and flagellates (heterotrophic and phototrophic). Subsamples of $100 \mathrm{ml}$ were filtered onto $0.2 \mu \mathrm{m}$ pore-size Durapore filters, submerged in lysis 
buffer $(40 \mathrm{mM}$ EDTA, $50 \mathrm{mM}$ Tris- $\mathrm{HCl}$ and $0.75 \mathrm{M}$ sucrose) and kept frozen $\left(-20^{\circ} \mathrm{C}\right.$ during the cruises and $-70^{\circ} \mathrm{C}$ afterwards). Cell lysis was performed by digestion with lysozyme followed by proteinase $\mathrm{K}$ and SDS treatments. DNA was purified by phenol/chloroform extraction and concentrated with a Centricon-100 (Millipore) as described previously (Díez et al. 2001a). Subsamples for FISH counts $(100 \mathrm{ml})$ were fixed with $0.2 \mu \mathrm{m}$-filtered formaldehyde ( $2 \%$ final concentration) at $4^{\circ} \mathrm{C}$ for 1 to $24 \mathrm{~h}$, subsequently filtered onto $0.6 \mu \mathrm{m}$ pore size polycarbonate filters (Poretics), and stored frozen.

Denaturing gradient gel electrophoresis (DGGE). We used $1 \mu$ of DNA extract as a template for PCR amplification of a $560 \mathrm{bp}$-long fragment of 18S rRNA genes using primers Euk1A and Euk516r-GC (Díez et al. 2001b). DGGE was performed with a DGGE-2000 system (CBS Scientific Company) as described previously (Díez et al. 2001b). Gels of 6\% polyacrylamide were prepared with a gradient of denaturant agent from 40 to $65 \%$ (100\% denaturant agent being $7 \mathrm{M}$ urea and $40 \%$ deionized formamide). PCR products (800 ng per sample) were loaded and the gel was run at $100 \mathrm{~V}$ for $16 \mathrm{~h}$ at $60^{\circ} \mathrm{C}$ in $1 \times$ TAE buffer $(40 \mathrm{mM}$ Tris [pH 7.4], $20 \mathrm{mM}$ sodium acetate, $1 \mathrm{mM}$ EDTA). The gel was stained with SybrGold (Molecular Probes) and DNA fragments were visualized in a Fluor-S MultiImager (Bio-Rad). High-resolution images were analyzed with the software Quantity One (Bio-Rad) in order to detect DGGE bands, quantify their intensity, and identify the same band position across the different lanes of the gel. A matrix was constructed with the presence and relative intensity of individual bands in each lane. This matrix was used to calculate a distance matrix with Euclidean distances and a dendrogram with UPGMA (Unweighted Pair-Group Method with Arithmetic averages) using Statistica 6.0 (StatSoft).

Gene clone libraries. 18S rRNA genes were amplified by PCR using 2 eukaryotic primer sets (Díez et al. 2001a,b): EukA and EukB that amplify the complete gene (ca. $1780 \mathrm{bp}$ ), and the DGGE set (without the GC clamp in the reverse primer) that amplifies only onethird of the gene (ca. $560 \mathrm{bp}$ ). PCR products from several reactions were cleaned with the QIAGEN PCR purification kit and cloned with the TOPO-TA cloning kit (Invitrogen). The presence of the 18S rRNA gene insert in the positive colonies was checked by PCR amplification with the same primers. In libraries with the first primer set (complete 18S rRNA genes), amplified inserts from single clones were digested with the restriction enzyme HaeIII (Invitrogen), electrophorized in $2.5 \%$ low-melting-point agarose (Invitrogen), and clones with the same restriction pattern were considered to belong to the same operational taxonomic unit (OTU). One clone per OTU was sequenced with the
Bigdye Terminator Cycle Sequencing Kit version 3.0 (PE Biosystems) and an ABI PRISM model 377 (version 3.3) automated sequencer using the internal primer Euk528f (Elwood et al. 1985). Thirteen clones were completely sequenced with 3 to 6 universal primers (the PCR primers plus $336 \mathrm{f}$ and 1209f). Sequence similarity of clones from the same OTU was above $99 \%$. In libraries with the second primer set (partial 18S rRNA genes), clones were directly sequenced with the vector primer M13f. In this case, clones were affiliated to the same OTU when their sequence similarity was above $99 \%$. This threshold was also applied to compare sequences from different libraries. The phylogenetic affiliation of clones was obtained by a basic local alignment search tool (BLAST) search (Altschul et al. 1997). Sequences were also submitted to BLAST searches with different regions for detecting chimeric artifacts (6 out of 207 sequences). Sequences were deposited in GenBank under accession numbers DQ121419 to DQ121431 and DQ647509 to DQ647544.

Fluorescent in situ hybridization (FISH). Five oligonucleotide probes specific to different MAST lineages were used: NS4 (Massana et al. 2002) and NS1A, NS1B, NS1C, and NS2 (Massana et al. 2006). Probes were supplied by Thermo Electron Corporation with a CY3 fluorophore at the 5' end. For FISH we followed the protocol detailed previously (Pernthaler et al. 2001). Filter portions (2 to 4 per sample) with protist cells were hybridized for $3 \mathrm{~h}$ at $46^{\circ} \mathrm{C}$ with each probe at $5 \mathrm{ng}^{-1}$ in a buffer of $900 \mathrm{nM} \mathrm{NaCl}, 20 \mathrm{mM}$ Tris- $\mathrm{HCl}$, $0.01 \%$ SDS and $30 \%$ formamide. Filters were washed for $15 \mathrm{~min}$ at $48^{\circ} \mathrm{C}$ in a buffer of $110 \mathrm{mM} \mathrm{NaCl}, 20 \mathrm{mM}$ Tris-HCl, $5 \mathrm{mM}$ EDTA and $0.01 \%$ SDS. Filters were then dried, counter-stained with DAPI, mounted on a slide with a mix of Citifluor and Vecta Shield (at a ratio of $4: 1$ ), and observed by epifluorescence microscopy under UV excitation (DAPI signal) and green light excitation (CY3 signal). Several transects (8 per sample on average) were inspected and mean MAST counts and SE were calculated; SE were typically $20 \%$ of the mean.

\section{RESULTS}

Unamended dark incubations with $3 \mu \mathrm{m}$-filtered surface seawater were conducted in 3 oceanographic areas: the Norwegian Sea, the NW Mediterranean and the Indian Ocean (Table 1). Most incubations resulted in a substantial growth of heterotrophic flagellates (HF), which increased from in situ concentrations of 0.4 to $1.2 \times 10^{3}$ cells ml ${ }^{-1}$ to 4 to $16 \times 10^{3}$ cells ml $^{-1}$ after 2 to $8 \mathrm{~d}$. The growth rate of HF assemblages was related to temperature, being around $0.5 \mathrm{~d}^{-1}$ below $10^{\circ} \mathrm{C}$ and around $1 \mathrm{~d}^{-1}$ above $20^{\circ} \mathrm{C}$. Only 3 incubations from the 
Table 1. Unamended dark incubations conducted in 3 marine areas. Station locations, sampling dates, and temperature $\left({ }^{\circ} \mathrm{C}\right)$ and chl a concentration ( $\mathrm{g} \mathrm{l}^{-1}$ ) of surface seawater are given. Dynamics of HF (heterotrophic flagellates) assemblages are indicated by abundance (cells ml-1) at the beginning and at the peak in $\mathrm{HF}$, day of the peak, and growth rate $\left(\mathrm{d}^{-1}\right)$. Abundance $\left(\mathrm{cells} \mathrm{ml}^{-1}\right)$ of MAST-1 and -4 cells estimated by FISH on the same 2 dates are also shown. The latter 3 incubations in the Indian Ocean did not show a significant increase in HF

\begin{tabular}{|c|c|c|c|c|c|c|c|c|c|c|c|c|}
\hline \multirow[t]{2}{*}{ Incubation } & \multirow[t]{2}{*}{ Location } & \multirow{2}{*}{$\begin{array}{c}\text { Date } \\
\text { (d/mo/yr) }\end{array}$} & \multirow{2}{*}{ Temp. } & \multirow[t]{2}{*}{ Chl a } & \multicolumn{4}{|c|}{$\mathrm{HF}$} & \multicolumn{2}{|c|}{ MAST-1 } & \multicolumn{2}{|c|}{ MAST-4 } \\
\hline & & & & & Day 0 & Peak & Peak day & $\mu$ & Day 0 & Peak & Day 0 & Peak \\
\hline \multicolumn{13}{|c|}{ Norwegian Sea } \\
\hline Coastal & $70^{\circ} 30^{\prime} \mathrm{N}, 20^{\circ} 04^{\prime} \mathrm{E}$ & $24 / 8 / 02$ & 12.6 & 0.936 & 652 & 5020 & 8 & 0.50 & 14 & 1136 & 73 & 78 \\
\hline Polar & $76^{\circ} 19^{\prime} \mathrm{N}, 23^{\circ} 45^{\prime} \mathrm{E}$ & 27/8/02 & 4.5 & 2.815 & 1003 & 4287 & 6 & 0.28 & 69 & 1401 & 90 & 190 \\
\hline Atlantic & $76^{\circ} 20^{\prime} \mathrm{N}, 03^{\circ} 59^{\prime} \mathrm{E}$ & 29/8/02 & 6.0 & 0.606 & 584 & 4196 & 6 & 0.46 & 8 & 1131 & 43 & 134 \\
\hline \multicolumn{13}{|c|}{ Blanes Bay (NW Mediterranean) } \\
\hline Nov 2001 & $41^{\circ} 40^{\prime} \mathrm{N}, 02^{\circ} 48^{\prime} \mathrm{E}$ & 06/11/01 & 18.0 & 0.410 & 710 & 8330 & 3 & 0.84 & 17 & 128 & 104 & 1812 \\
\hline Jan 2005 & $41^{\circ} 40^{\prime} \mathrm{N}, 02^{\circ} 48^{\prime} \mathrm{E}$ & 20/1/05 & 13.0 & 0.510 & 412 & 4021 & 7 & 0.66 & 1 & 1423 & 26 & 65 \\
\hline Feb 2005 & $41^{\circ} 40^{\prime} \mathrm{N}, 02^{\circ} 48^{\prime} \mathrm{E}$ & $15 / 2 / 05$ & 12.1 & 1.340 & 495 & 3055 & 3 & 0.90 & 9 & 43 & 54 & 858 \\
\hline Jul 2005 & $41^{\circ} 40^{\prime} \mathrm{N}, 02^{\circ} 48^{\prime} \mathrm{E}$ & $05 / 7 / 05$ & 24.0 & 0.110 & 1425 & 11228 & 3 & 0.75 & 25 & 169 & 80 & 1811 \\
\hline Sep 2005 & $41^{\circ} 40^{\prime} \mathrm{N}, 02^{\circ} 48^{\prime} \mathrm{E}$ & $13 / 9 / 05$ & 26.1 & 0.270 & 1222 & 16546 & 2 & 1.25 & 31 & 86 & 18 & 2526 \\
\hline \multicolumn{13}{|l|}{ Indian Ocean } \\
\hline Coastal & $35^{\circ} 03^{\prime} \mathrm{S}, 23^{\circ} 44^{\prime} \mathrm{E}$ & $16 / 5 / 03$ & 20.9 & 1.300 & 687 & 4597 & 2 & 0.98 & 25 & 267 & 101 & 621 \\
\hline Madagascar & $33^{\circ} 18^{\prime} \mathrm{S}, 45^{\circ} 22^{\prime} \mathrm{E}$ & $21 / 5 / 03$ & 20.9 & 0.171 & 499 & 1212 & 4 & 0.87 & 6 & 415 & 19 & 9 \\
\hline Gyre & $31^{\circ} 50^{\prime} \mathrm{S}, 52^{\circ} 37^{\prime} \mathrm{E}$ & $23 / 5 / 03$ & 21.6 & 0.147 & 626 & - & & & & & & \\
\hline Osborn & $17^{\circ} 11^{\prime} \mathrm{S}, 83^{\circ} 41^{\prime} \mathrm{E}$ & 01/6/03 & 25.2 & 0.073 & 450 & - & & & & & & \\
\hline Keeling & $12^{\circ} 13^{\prime} \mathrm{S}, 96^{\circ} 47^{\prime} \mathrm{E}$ & 06/6/03 & 28.5 & 0.122 & 719 & - & & & & & & \\
\hline
\end{tabular}

Central Indian Ocean did not show significant growth of HF. The detailed microbial dynamics (direct counts of DAPI stained cells) of the 3 incubations from the Norwegian Sea are shown in Fig. 1. The other incubations followed similar dynamics (not shown). Initially, bacterial numbers increased 2 to 3 times, followed by increasing numbers of $\mathrm{HF}$ a few days later coincident with the decrease in bacterial numbers. Photosynthetic flagellates and Synechococcus decreased continuously in numbers during the incubations, owing to dark conditions and perhaps to predation by HF.

The potential for growth of uncultured HF was analyzed by counting MAST-1 (with a mix of 3 probes against 3 related groups) and MAST- 4 cells by FISH at the beginning and at the peak of HF (Table 1). In most incubations, including the 3 oceanographic areas, there was substantial growth of at least 1 of the 2 groups, and both groups often grew together. Initially, average MAST-1 and MAST- 4 concentrations were 21 and $61 \mathrm{cells} \mathrm{ml}^{-1}$, and during the peak they reached values above $10^{3}$ cells ml ${ }^{-1}$ (in 4 and 3 incubations, respectively) and between $10^{2}$ and $10^{3}$ cells ml $^{-1}$ (in 4 incubations each). At the peak of HF, these 2 MAST groups accounted on average for $27 \%$ of heterotrophic flagellates, indicating that they form a significant fraction of the grown HF.

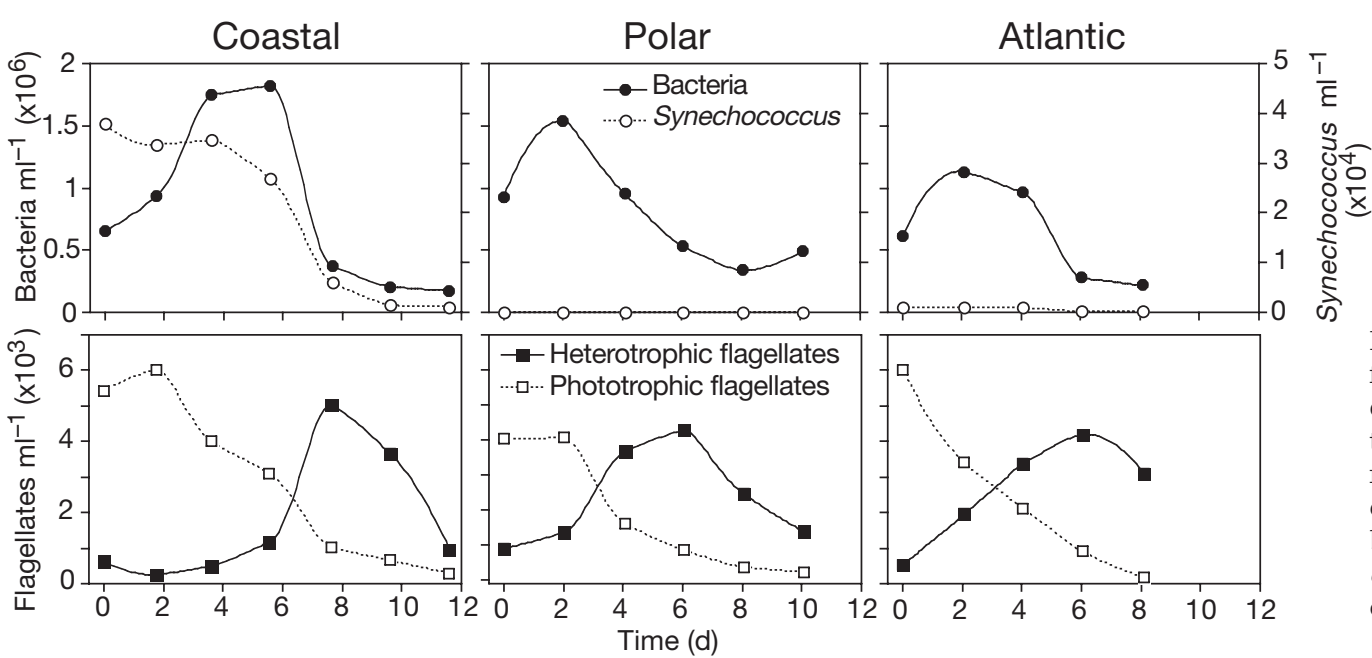

Fig. 1. Abundance of different microbial groups during 3 incubations from the Norwegian Sea estimated by DAPI cell counts. Upper panels: bacteria and Synechococcus. Lower panels: heterotrophic and phototrophic flagellates 

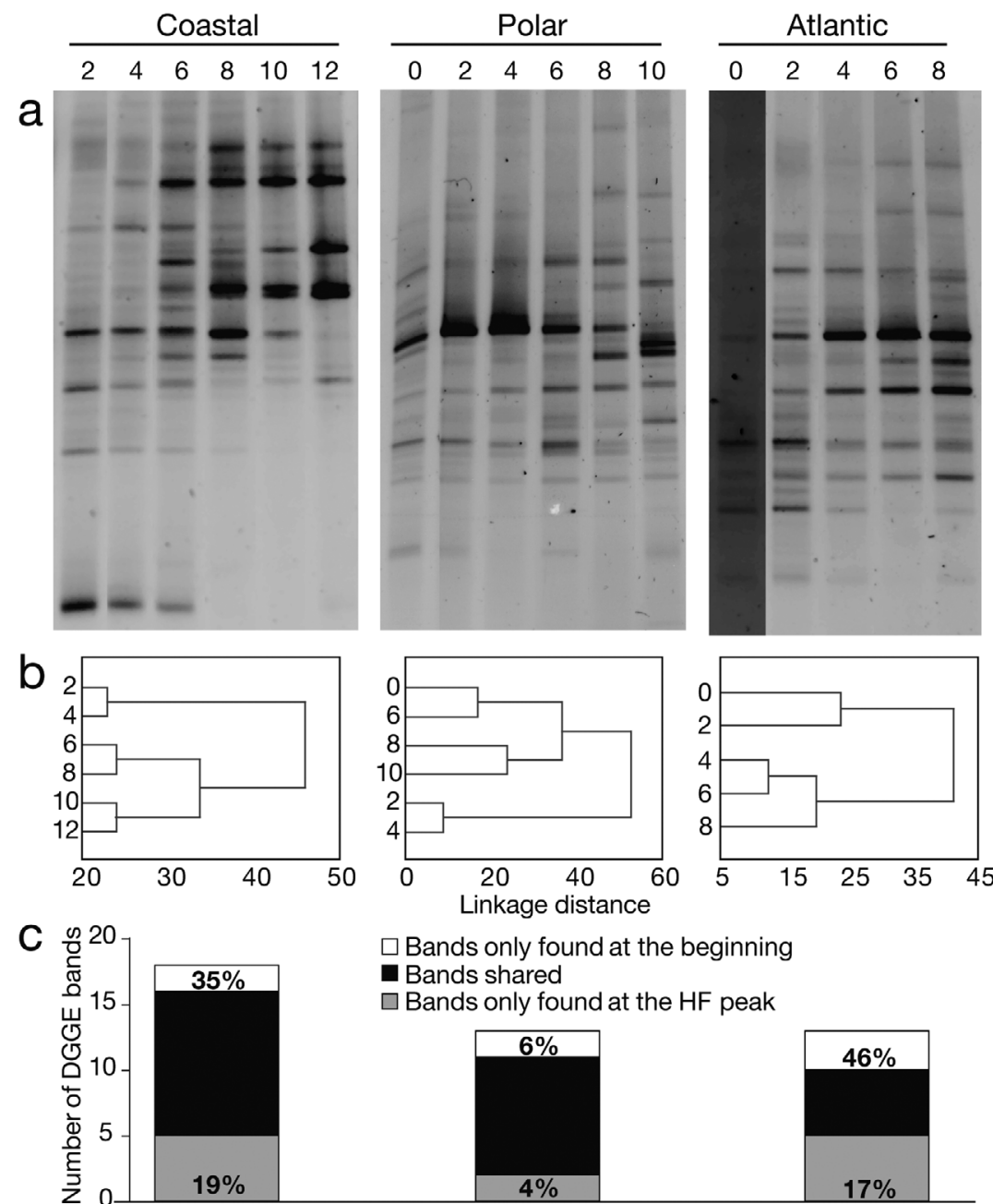

$\square$ Bands only found at the beginning

Bands shared

$\square$ Bands only found at the HF peak
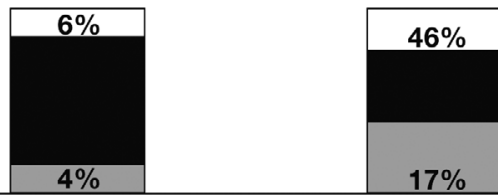

Fig. 2. (a) Inverted images of DGGE gels showing the fingerprint each day during incubations from the Norwegian Sea. (b) Cluster analysis relating DGGE fingerprints. (c) Comparison of DGGE fingerprints (number and band intensity) between the initial sample and sample with maximal HF abundance (Day 8 in Coastal and Day 6 in Polar and Atlantic). Number of bands is separated among those found only at the beginning, those found only at the HF peak, and those shared. Values above histograms are \% of band intensity accounted for by unique bands fingerprints (Fig. 2b). A finer analysis of the protists growing in each incubation was conducted by comparing the number and intensity of DGGE bands between the initial sample and the sample at the peak of HF (Fig. 2c). Minor changes in protist composition were observed in the Polar incubation: most band positions were shared between these 2 samples, and the few DGGE bands disappearing or appearing during the incubation were weak (6 and $4 \%$ of signal intensity). Coastal and Atlantic incubations behaved differently, with a few intense bands (35 and 46\% band intensity) disappearing from the original assemblage and the bands that appeared being relatively weak. This implied that most of the protists selected during these incubations were already well represented in the original sample. For instance, in the Atlantic incubation, shared bands accounted for $54 \%$ of intensity at the beginning and $83 \%$ of intensity at the date of maximal HF abundance.

To obtain phylogenetic information on the growing protists, we prepared $18 \mathrm{~S}$ rRNA gene clone libraries from the date of maximal HF abundance (Day 8 in Coastal and Day 6 in Polar and Atlantic incubations). Three libraries contained the complete 18S rRNA genes (CD8, PD6 and AD6; 36, 52 and 54 clones, respectively) and 2 libraries contained just onethird of the gene (CD8S and AD6S; 30 and 32 clones, respectively). In the 5 libraries, 10 to $20 \%$ of clones affiliated with putative photosynthetic groups (Fig. 3), which agreed with the dominance of HF observed by microscopy in
The changes in protist diversity during the incubations from the Norwegian Sea were followed by DGGE (Fig. 2a). Protist diversity varied over time, and the changes were gradual. DGGE bands were normally observed on consecutive dates, and each sample was generally more similar to the previous and the next one than to others, as shown in cluster analyses of DGGE

Fig. 3. Percentage of clones within phototrophic groups and putative heterotrophic groups (MASTs, novel alveolates, chrysophytes and others) in 18S rRNA gene libraries from Norwegian samples with maximal HF abundance. Libraries CD8, PD6 and AD6 contain the whole 18S rRNA gene and libraries CD8S and AD6S only one-third

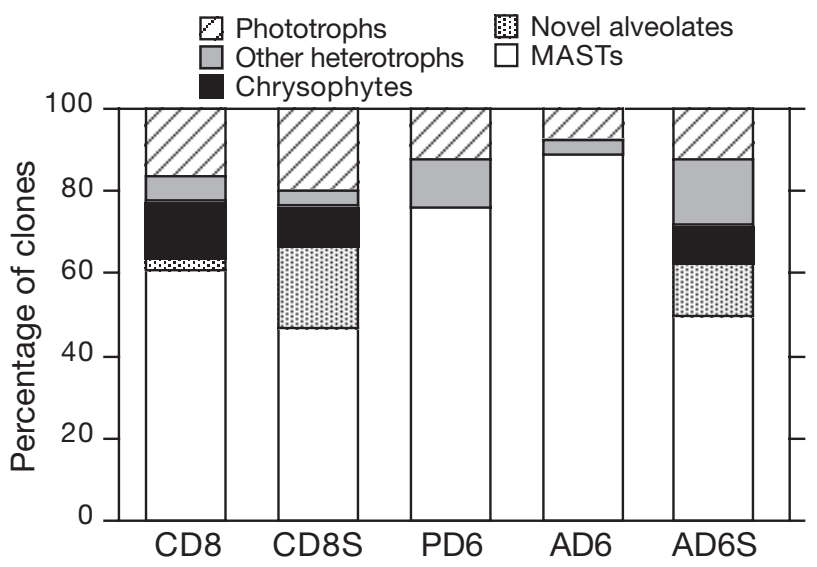


these samples (more than $80 \%$ of the cells). The putative heterotrophic groups were dominated by uncultured protists found in marine molecular surveys, particularly MASTs (which accounted for 50 to $90 \%$ of clones) and novel alveolates. Chrysophytes also formed a significant fraction of clones. Libraries from the same sample with the 2 primer sets gave somewhat different pictures of protist diversity. For example, in the Atlantic sample, novel alveolates and chrysophytes were not found in the AD6 library.

The phylogenetic affiliation of our sequences is given in Table 2, with each row indicating a single
OTU and its clonal representation in the 5 libraries. Several OTUs were found in the 2 libraries from the same sample, showing that different primer sets were retrieving the same sequences (but at different clonal abundance). Important exceptions were the OTUs represented by the sequences CD8.09 ( 7 clones in AD6S and none in AD6) and CD8.03 (10 clones in CD8 and none in CD8S). In addition, the OTUs represented by a single clone were seldom found in the other libraries, an indication of library under-sampling. When the 3 samples are compared, similar MASTs were selected in Polar and Atlantic incubations, whereas a somewhat

Table 2. Phylogenetic affiliation of clones in incubations from the Norwegian Sea. Each row represents a different operational taxonomic unit (OTU), with its representative clone and best match in GenBank and the number of clones in each genetic library.

Libraries CD8, PD6 and AD6 contain the whole 18S rRNA gene (ca. 1780 bp) and libraries CD8S and AD6S only 560 bp

\begin{tabular}{|c|c|c|c|c|c|c|c|}
\hline \multirow[t]{2}{*}{ Group } & \multirow{2}{*}{ Clone name } & \multirow{2}{*}{ Best match (\%) } & \multicolumn{2}{|c|}{ Coastal, Day 8} & \multirow{2}{*}{$\begin{array}{c}\text { Polar, Day } 6 \\
\text { PD6 }\end{array}$} & \multicolumn{2}{|c|}{ Atlantic, Day 6} \\
\hline & & & CD8 & CD8S & & AD6 & AD6S \\
\hline \multirow[t]{2}{*}{ MAST-1A } & AD6.02 & DH144-EKD10 (99.4) & - & - & 32 & 35 & 5 \\
\hline & AD6.05 & ME1-21 (98.0) & - & - & - & 5 & - \\
\hline MAST-1B & CD8.09 & RA000412.91 (99.4) & 5 & 12 & 3 & - & 7 \\
\hline \multirow[t]{2}{*}{ MAST-1C } & CD8.02 & ME1-22 (99.2) & 6 & 2 & - & - & - \\
\hline & AD6.03 & FV18_2F12 (99.8) & - & - & 3 & 8 & 3 \\
\hline MAST-2 & CD8.03 & DH148-5-EKD53 (99.7) & 10 & - & 2 & - & 1 \\
\hline MAST-7 & CD8.12 & UEPACLp5 (99.7) & 1 & - & - & - & - \\
\hline \multirow{2}{*}{ Marine alveolates-I } & CD8.17 & UEPAC36p4 (98.9) & 1 & 3 & - & - & - \\
\hline & CD8S.30 & OLI11511 (98.0) & - & 1 & - & - & - \\
\hline \multirow{4}{*}{ Marine alveolates-II } & CD8S.12 & UEPACFp5 (99.8) & - & 1 & - & - & 2 \\
\hline & CD8S.16 & TWS096 (95.8) & - & 1 & - & - & - \\
\hline & AD6S.01 & UEPACEp3 (94.3) & - & - & - & - & 1 \\
\hline & AD6S.30 & UEPACCp3 (99.5) & - & - & - & - & 1 \\
\hline \multirow[t]{6}{*}{ Chrysophyceae } & CD8.06 & Spumella JBAF33 (91.2) & 1 & - & - & - & - \\
\hline & CD8.15 & NOR50.37 (98.4) & 2 & - & - & - & 1 \\
\hline & CD8.18 & ENI42482.00342 (99.2) & 2 & 1 & - & - & - \\
\hline & CD8S.27 & NS51A157 (95.0) & - & 2 & - & - & - \\
\hline & AD6S.11 & LG44-07 (95.9) & - & - & - & - & 1 \\
\hline & AD6S.18 & LG35-09 (95.7) & - & - & - & - & 1 \\
\hline \multirow[t]{3}{*}{ Telonema } & PD6.20 & Telonema antarcticum (97.3) & - & - & 1 & - & - \\
\hline & AD6S.04 & Telonema antarcticum (94.0) & - & - & - & - & 2 \\
\hline & AD6S.06 & Telonema antarcticum (97.3) & - & - & - & - & 1 \\
\hline Choanoflagellates & PD6.09 & M1_18E10 (97.1) & - & - & 1 & - & - \\
\hline \multirow[t]{2}{*}{ Cercozoa } & CD8S.31 & Allas sp. (93.1) & - & 1 & - & - & - \\
\hline & AD6.07 & NOR26.21 (98.7) & - & - & - & 1 & 1 \\
\hline \multirow[t]{3}{*}{ Ciliates } & CD8.05 & MD65.05 (98.7) & 1 & - & - & 1 & - \\
\hline & CD8.16 & Strombidium SNB99-2 (97.2) & 1 & - & - & - & - \\
\hline & AD6S.28 & NS371C63 (96.9) & - & - & - & - & 1 \\
\hline Fungi & PD6.12 & RA000609.30 (99.3) & - & - & 4 & - & - \\
\hline Prasinophyceae & AD6.08 & A1_E023 (99.3) & - & - & - & 2 & - \\
\hline \multirow[t]{2}{*}{ Prymnesiophyceae } & CD8S.01 & Phaeocystis jahnii (95.9) & - & 1 & - & - & - \\
\hline & PD6.17 & Chrysochromulina scutellum (97.4) & - & - & 4 & 1 & - \\
\hline \multirow[t]{2}{*}{ Cryptophyceae } & AD6.09 & Plagioselmis prolonga (100) & - & - & - & 1 & - \\
\hline & CD8S.08 & LG07-11 (94.9) & - & 2 & - & - & - \\
\hline Novel algae & AD6S.10 & He000803-72 (98.4) & - & - & - & - & 3 \\
\hline \multirow[t]{2}{*}{ Diatoms } & CD8S.05 & Chaetoceros rostratus (97.8) & - & 1 & - & - & 1 \\
\hline & PD6.14 & Skeletonema costatum (99.5) & - & - & 2 & - & - \\
\hline Bolidophyceae & CD8S.09 & Bolidomonas pacifica (99.3) & - & 1 & - & - & - \\
\hline \multirow[t]{2}{*}{ Dictyochophyceae } & CD8.07 & Pteridomonas danica (96.3) & 1 & 1 & - & - & - \\
\hline & CD8.08 & Florenciella parvula (99.7) & 1 & - & - & - & - \\
\hline \multirow[t]{2}{*}{ Dinoflagellates } & CD8.04 & Prorocentrum mexicanum (99.3) & 3 & - & - & - & - \\
\hline & CD8.10 & FV23_1E1 (97.4) & 1 & - & - & - & - \\
\hline
\end{tabular}


Fig. 4. Dynamics of 5 MAST groups during incubations from the Norwegian Sea. Upper panels: cell abundance determined by FISH counts (mean and SE). Lower panels: total MAST abundance and contribution of MAST cells to the HF count
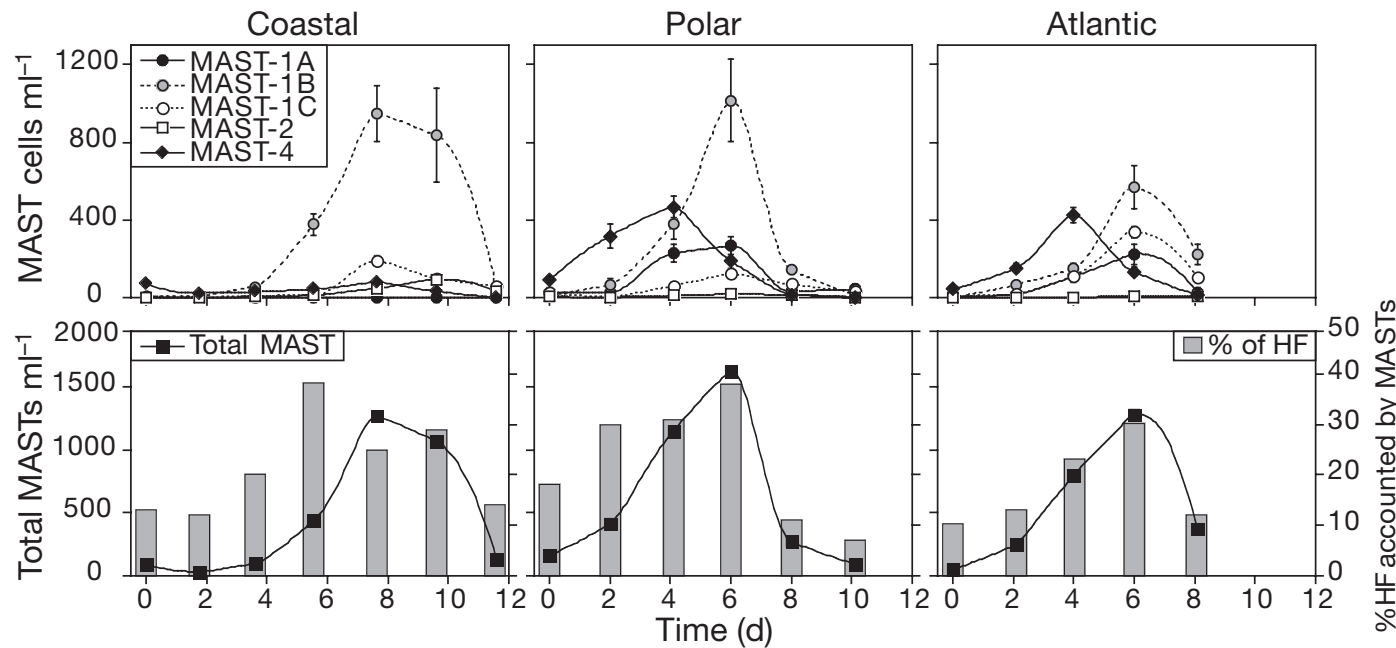

different assemblage developed in the Coastal incubation. Thus, the dominant OTU in the Polar-Atlantic libraries (clone AD6.02 within MAST-1A) was not found in the Coastal library, and a different MAST-1C was found in Coastal (CD8.02) and Polar-Atlantic incubations (AD6.03). Nevertheless, the same MAST-1B sequence was found in the 3 cases. Other uncultured protists found in the libraries were the novel alveolates, both Group I and II, and the chrysophytes. Sequences from the later group were unrelated to known chrysophytes and formed 3 independent lineages represented by CD8.06 (including AD6S.11), CD8.15 (including CD8S.27), and CD8.18 (including AD6S.18). Other heterotrophic groups found at low clonal abundance were Telonema, choanoflagellates, cercozoans, fungi, and ciliates.

The dynamics of MAST cells during the Norwegian Sea incubations were followed by FISH counts with probes specific to 5 lineages. The targeted cells were spherical and measured around 2 to $3 \mu \mathrm{m}$ (MAST-4), 4 to $5 \mu \mathrm{m}$ (MAST-1B and -2), and 6 to $7 \mu \mathrm{m}$ (MAST-1A and $-1 \mathrm{C}$ ). These groups grew substantially in at least 2 of the 3 incubations (Fig. 4), with growth rates of 0.4 to $1 \mathrm{~d}^{-1}$, and attained $10^{2}$ to $10^{3}$ cells ml ${ }^{-1}$ (Table 3 ). At the peak of abundance of $\mathrm{HF}$, the 5 MAST groups accounted for around 1500 cells ml $\mathrm{m}^{-1}$ or 30 to $40 \%$ of HF cells (Fig. 4). The proportion of HF comprised of MASTs doubled during the incubations, as these cells already accounted for 10 to $20 \%$ of HF in the initial sample. However, the dynamics of the 5 groups considered together obscured particular trends. MAST-4 cells were the most abundant in situ, but they did not thrive well in the incubations and always decreased their contribution to HF (Table 3). These cells did not grow in the Coastal incubation and peaked before the other groups in the other 2 cases. In contrast, the other MAST groups showed a marked increase in their contribution to HF during the incubations. MAST-1B cells were the most successful in all 3 cases and reached the highest abundance (up to $10^{3}$ cells $\mathrm{ml}^{-1}$ ). MAST-1A and MAST-1C cells grew at similar rates in the 3 incubations (maximal abundances of 100 to $300 \mathrm{cells} \mathrm{ml}^{-1}$ ), with the remarkable absence of MAST-1A cells from the Coastal incubation. MAST-2 cells grew moderately in the 3 incubations and never reached abundances above 100 cells $\mathrm{ml}^{-1}$.

Finally, our data set allowed comparison of the representation of specific MAST groups in clone libraries with their actual cell percentage estimated by FISH direct counts (Fig. 5). The primer set amplifying the complete 18S rRNA gene gave a very biased view of MAST presence in the analyzed samples, with MAST$1 \mathrm{~A}$ and -2 severely overestimated and MAST-1B

Table 3. Abundance (cells $\mathrm{ml}^{-1}$ ) and growth rates $\left(\mathrm{d}^{-1}\right)$ of MAST cells in incubations from the Norwegian Sea. Growth rates were calculated using 3 to 4 time points of exponential increase. The last column shows the quotient between the \% contribution of the specific group to total HF at the peak and at the beginning of the experiment. nd: not detected

\begin{tabular}{|cccccc|}
\hline & & \multicolumn{2}{c}{ Abundance } & Growth & Increase \\
& & Day 0 & Maximal & rate & HF \\
\hline MAST-1A & Coastal & 1 & nd & nd & nd \\
& Polar & 28 & 266 & 0.59 & 2.5 \\
& Atlantic & 2 & 225 & 0.81 & 9.9 \\
MAST-1B & Coastal & 3 & 947 & 0.79 & 9.9 \\
& Polar & 12 & 1016 & 0.75 & 7.7 \\
& Atlantic & 1 & 567 & 0.54 & 7.7 \\
MAST-1C & Coastal & 9 & 189 & 0.76 & 5.4 \\
& Polar & 29 & 124 & 0.40 & 1.7 \\
& Atlantic & 5 & 338 & 0.71 & 8.3 \\
MAST-2 & Coastal & 2 & 95 & 0.52 & 8.1 \\
& Polar & 5 & 19 & 0.57 & 1.3 \\
& Atlantic & 2 & 9 & nd & nd \\
MAST-4 & Coastal & 73 & 78 & nd & nd \\
& Polar & 90 & 467 & 0.40 & 0.3 \\
& Atlantic & 43 & 423 & 0.57 & 0.4 \\
& & & & & \\
\hline
\end{tabular}




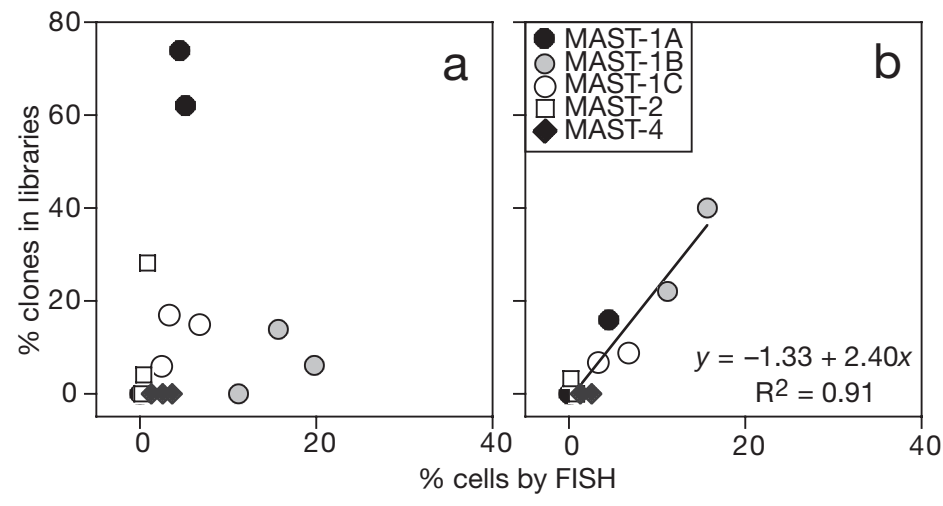

Fig. 5. Comparison of MAST signals found by FISH (\% of cells with respect to total protist counts) and clone libraries (\% of clonal abundance) using (a) primers for the complete gene (libraries CD8, PD6 and AD6) and (b) primers for partial genes (libraries CDS8 and ADS6)

underestimated (Fig. 5a). In contrast, the primer set amplifying one-third of the gene (in fact, the set that is regularly used in DGGE studies) provided very good correlation between clonal representation and cell abundance of the 5 MAST groups, where all groups are similarly over-represented 2.4 times (Fig. 5b).

\section{DISCUSSION}

Seawater incubations enriched with organic matter additions are typically conducted as first stages in the isolation of $\mathrm{HF}$ and to facilitate live and electronic microscopy observations (Fenchel 1986, Vørs et al. 1995). This addition usually selects for fast-growing bacteria, typically larger than in situ bacteria, and only some flagellates able to graze on these develop. This was nicely exemplified in a series of enrichment cultures done in North Atlantic coastal waters (Lim et al. 1999). In the latter study, addition of yeast extract increased bacterial abundance by 2 orders of magnitude (up to $10^{8}$ cells ml ${ }^{-1}$ ), and Paraphysomonas imperforata dominated most enrichments (up to $98 \%$ of cells). However, this flagellate was barely found in the environment. Thus, culture bias in rich media would explain why cultured HF are scarce in molecular surveys (they are readily enriched but have low in situ abundance) and why these surveys retrieve uncultured lineages (they are outcompeted during isolation). This is a well-known scenario for marine prokaryotes: the numerically dominant cells do not belong to easily cultured strains but to lineages first discovered in molecular surveys (Giovannoni et al. 1990). These prokaryotes were later found to be very abundant in FISH counts (Morris et al. 2002), and some were eventually cultured by serial dilution in low-nutrient media (Rappé et al. 2002). This illustrates the fruitful conver- gence of molecular surveys and culture attempts to study the microbial world, and the potential advantage of simulating the oligotrophic nature of the marine environment.

Our seawater incubations were unamended: bacteria grew on autochthonous substrates, and maintained their abundance at realistic levels; thus, we expected the growth of typical in situ flagellates. The preparation was easy, including only a prefiltration, which simplified the assemblage by leaving small protists without their predators, and dark incubation, which prevented the growth of phototrophic cells. In our samples, this setup resulted in a change from an in situ protist assemblage dominated by phototrophic cells to another dominated by heterotrophic cells, which increased 3 to 30 times. Since the incubations were unamended, there was the possibility that bacteria might not be stimulated and that flagellates consequently might not grow, as occurred in samples from very poor areas of the Central Indian (Table 1) or Atlantic Oceans (Jürgens et al. 2000). In most instances, however, growth was obtained. The main drawback of our approach is that these events are short-lived and unstable: flagellate numbers decrease rapidly after their maximal abundance, likely because of prey exhaustion. If cells of uncultured protists develop, these incubations can hardly lead directly to successful isolations. Instead, they can be used to infer metabolic and kinetic features of uncultured protists, and provide information and become the first stages for more focused isolating attempts.

The significant increase in HF in our unamended incubations (Table 1) was paralleled by an increase in MAST-1 and/or MAST-4 cells. These organisms are yet uncultured, but recent studies indicate that they are heterotrophic flagellates with a global distribution and significant abundance in the world's oceans (Massana et al. 2006). It seemed that MAST-1 cells were favored in colder systems, and MAST-4 in warmer systems, but more data are needed to support this observation. These cells also appear to grow in North Atlantic water incubated without prefiltration (Countway et al. 2005): even though FISH counts were not provided, the authors reported a marked change in diversity and MAST-1 and -4 sequences were still found after 3 days of incubation. A closer look at the incubations from the Norwegian Sea by DGGE, clone libraries and FISH revealed that a diverse assemblage of MAST cells was growing in each case. However, the same MAST-1B cell appeared to be the most important in the 3 cases, and 2 of the incubations (Polar and Atlantic) revealed very similar dynamics. This is surprising given the particularity of each initial sample (with coastal, polar and Atlantic influences) and 
the geographic distance between them (hundreds of nautical miles).

A detailed analysis of clone libraries revealed which protists besides MASTs could grow in the incubations. Other uncultured groups common in picoplankton surveys were retrieved, such as the marine alveolates Groups I and II. The trophic role of these cells remains unknown; however, it has been suggested that most of them are parasites (Groisillier et al. 2006). This deserves further research, because the growth of parasites in our exclusively picoplanktonic incubations was unexpected. A significant set of sequences belonged to chrysophytes, a group known to contain phototrophic, mixotrophic and heterotrophic flagellates, but they did not affiliate with any of the phylogenetic clusters described so far (Andersen et al. 1999). Interestingly, these uncultured chrysophytes are also seldom found in environmental surveys, highlighting the large extent of protist diversity and the different picture obtained depending on the window of observation. Finally, a few sequences were affiliated with known heterotrophic flagellates, such as choanoflagellates, cercozoans and Telonema, whereas ciliate sequences likely derived from cell breakage during the initial prefiltration.

Clone libraries are essential to obtain a phylogenetic description of the microbial taxa in a given sample, but provide poor estimates of actual abundance owing to PCR biases (von Wintzingerode et al. 1997, Stoeck et al. 2006) and the varying copy number of the rRNA operon in different organisms (Zhu et al. 2005). In our study, we prepared clone libraries using 2 primer sets from the same samples. Some sequences were found with both sets, but others were not. The primer bias detected here was not as extreme as described recently (Stoeck et al. 2006), because the most frequent OTUs were generally found in the 2 libraries and most non-shared OTUs also had low clonal abundance (so their uniqueness was a consequence of undersampling). When comparing the clonal representation (even in these libraries with only 30 to 50 clones) of MAST groups with their true cell abundance estimated by FISH, it is clear that the 2 primer sets did not perform equally. The first set (Fig. 5a) gave a very biased view of MAST presence, whereas the second set (Fig. 5b) gave a good correlation where all groups were similarly overrepresented. In summary, we see the clone libraries as the only way to obtain a list of taxa in a given assemblage, with the use of different primer sets improving the length and accuracy of the list; however, the quantification of each taxa requires other methods such as FISH.

We used 5 FISH probes to follow the dynamics of the corresponding MAST cells in incubations from the Norwegian Sea. These 5 groups have been shown to be heterotrophic flagellates with mean global abun- dances of 5 to 10 (MAST-1A and -2), 30 to 40 (MAST$1 \mathrm{~B}$ and $-1 \mathrm{C}$ ) and 130 cells $\mathrm{ml}^{-1}$ (MAST-4) (Massana et al. 2006). MAST-1B cells were the most successful in the 3 incubations (sequence analyses suggest that they were always the same genotype, both within and among incubations), followed by MAST-1A cells (only 1 genotype) and MAST-1C cells (2 different genotypes). MAST-2 cells grew moderately and MAST-4 cells peaked before the other groups, which could explain why they were not detected in clone libraries. Thus, the FISH data identified the particular dynamics of each MAST group, with different groups peaking at different times or developing only in given incubations. The growth rates of MAST cells ranged from 0.4 to $1 \mathrm{~d}^{-1}$, values that are several times lower than the maximal growth rates of cultured strains (3 to $6 \mathrm{~d}^{-1}$, Fenchel 1986), even if corrected for differences in experimental temperatures (Montagnes et al. 2003). In fact, the measured growth rates of MAST cells were remarkably similar to growth rates of marine $\mathrm{HF}$ assemblages, both in this study (Table 1) and others (summarized by Laybourn-Parry \& Parry 2000). This indicates that MAST cells have growth dynamics typical of in situ heterotrophic flagellates.

We observed the growth of uncultured protists in unamended incubations prepared to promote the development of HF with coastal and offshore surface waters from the Mediterranean Sea, the Norwegian Sea and the Indian Ocean. These protists, including different MAST cells, have been found in molecular surveys from distant oceanic areas, indicating a global distribution, but have not yet been retrieved in culture. Incubations such as those performed in this study help to assess some of their biological properties and growth requirements, and will be used as first steps in more focused culturing attempts. This experimental protocol could in principle be used also for other uncultured protists, both heterotrophic and phototrophic.

Acknowledgements. This study was supported by projects ESTRAMAR (CTM2004-12631/MAR, MEC) and TRANSINDICO (REN2002-10951-E/MAR, MCyT) granted to R.M. and ARCTIC-2000 (REN2001-4909-E/ANT, MCyT) and Marine Genomics (FP6- 505403, EU) to C.P.A. Chief-scientists R. Ingvaldsen and D. Blackman and the crews of RV 'Johan Hjort' (Norwegian Marine Research Institute) and RV 'Melville' (Scripps Institution of Oceanography) provided an excellent sampling environment. We thank W. Eikrem and E. Goetze for inviting us on board, and S. Garcia-Piqué and V. Balagué for laboratory assistance.

\section{LITERATURE CITED}

Altschul SF, Madden TL, Schäffer AA, Zhang J, Zhang Z, Miller W, Lipman DJ (1997) Gapped BLAST and PSIBLAST: a new generation of protein database search programs. Nucleic Acids Res 25:3389-3402 
Andersen RA, van de Peer Y, Potter D, Sexton JP, Kawachi M, LaJeunesse $T$ (1999) Phylogenetic analysis of the SSU rRNA from members of the Chrysophyceae. Protist 150: 71-84

Arndt H, Dietrich D, Auer B, Cleven EJ, Gräfenhan T, Weitere M, Mylnikov AP (2000) Functional diversity of heterotrophic flagellates in aquatic ecosystems. In: Leadbeater BSC, Green JC (eds) The flagellates: unity, diversity and evolution. Taylor \& Francis Press, London, p 240-268

Azam F, Fenchel T, Field JG, Gray JS, Meyer-Reil LA, Thingstad F (1983) The ecological role of water-column microbes in the sea. Mar Ecol Prog Ser 10:257-263

Boenigk J, Arndt H (2002) Bacterivory by heterotrophic flagellates: community structure and feeding strategies. Antonie van Leeuwenhoek 81:465-480

Caron DA, Lim EL, Miceli G, Waterbury JB, Valois FW (1991) Grazing and utilization of chroococcoid cyanobacteria and heterotrophic bacteria by protozoa in laboratory cultures and a coastal plankton community. Mar Ecol Prog Ser 76:205-217

Caron DA, Peele ER, Lim EL, Dennett MR (1999) Picoplankton and nanoplankton and their trophic coupling in the surface waters of the Sargasso Sea south of Bermuda. Limnol Oceanogr 44:259-272

Countway PD, Gast RJ, Savai P, Caron DA (2005) Protistan diversity estimates based on 18S rDNA from seawater incubations in the Western North Atlantic. J Eukaryot Microbiol 52:95-106

Díez B, Pedrós-Alió C, Massana R (2001a) Study of genetic diversity of eukaryotic picoplankton in different oceanic regions by small-subunit rRNA gene cloning and sequencing. Appl Environ Microbiol 67:2932-2941

Díez B, Pedrós-Alió C, Marsh TL, Massana R (2001b) Application of denaturing gradient gel electrophoresis (DGGE) to study the diversity of marine picoeukaryotic assemblages and comparison of DGGE with other molecular techniques. Appl Environ Microbiol 67:2942-2951

Elwood HJ, Olsen GJ, Sogin ML (1985) The small-subunit ribosomal RNA gene sequences from the hypotrichous ciliates Oxytricha nova and Stylonychia pustulata. Mol Biol Evol 2:399-410

Fenchel T (1986) The ecology of heterotrophic microflagellates. Adv Microb Ecol 9:57-97

Giovannoni SJ, Britschgi TB, Moyer CL, Field KG (1990) Genetic diversity in Sargasso Sea bacterioplankton. Nature 345:60-63

Groisillier A, Massana R, Valentin K, Vaulot D, Guillou L (2006) Genetic diversity and habitats of two enigmatic marine alveolate lineages. Aquat Microb Ecol 42:277-291

Jürgens K, Gasol JM, Vaqué D (2000) Bacteria-flagellate coupling in microcosm experiments in the Central Atlantic Ocean. J Exp Mar Biol Ecol 245:127-147

Laybourn-Parry J, Parry J (2000) Flagellates and the microbial loop. In: Leadbeater BSC, Green JC (eds) The flagellates: unity, diversity and evolution. Taylor \& Francis Press, London, p 216-239

Lee WJ, Patterson DJ (1998) Diversity and geographic distribution of free-living heterotrophic flagellates - analysis by PRIMER. Protist 149:229-244

Lim EL, Dennet MR, Caron DA (1999) The ecology of Paraphysomonas imperforata based on studies employing oligonucleotide probe identification in coastal water samples and enrichment cultures. Limnol Oceanogr 44:37-51

Lovejoy C, Massana R, Pedrós-Alió C (2006) Diversity and distribution of marine microbial eukaryotes in the Arctic Ocean and adjacent seas. Appl Environ Microbiol 72:3085-3095
Massana R, Guillou L, Díez B, Pedrós-Alió C (2002) Unveiling the organisms behind novel eukaryotic ribosomal DNA sequences from the ocean. Appl Environ Microbiol 68: $4554-4558$

Massana R, Castresana J, Balagué V, Guillou L, Romari K, Groisillier A, Valentin K, Pedrós-Alió C (2004) Phylogenetic and ecological analysis of novel marine stramenopiles. Appl Environ Microbiol 70:3528-3534

Massana R, Terrado R, Forn I, Lovejoy C, Pedrós-Alió C (2006) Distribution and abundance of uncultured heterotrophic flagellates in the world oceans. Environ Microbiol 8: 1515-1522

Montagnes DJS, Kimmance SA, Atkinson D (2003) Using $Q_{10}$ : can growth rates increase linearly with temperature? Aquat Microb Ecol 32:307-313

Moon-van der Staay SY, Watcher RD, Vaulot D (2001) Oceanic 18S rDNA sequences from picoplankton reveal unsuspected eukaryotic diversity. Nature 409:607-610

Morris RM, Rappé MS, Connon SA, Vergin KL, Siebold WA, Carlson CA, Giovannoni SJ (2002) SAR11 clade dominates ocean surface bacterioplankton communities. Nature 420 : $806-810$

Not F, Massana R, Latasa M, Marie D and 5 others (2005) Late summer community composition and abundance of photosynthetic picoeukaryotes in Norwegian and Barents Seas. Limnol Oceanogr 50:1677-1686

Pernthaler J (2005) Predation on prokaryotes in the water column and its ecological implications. Nat Rev Microbiol 3:537-546

Pernthaler J, Glöckner FO, Schönhuber W, Amann R (2001) Fluorescence In Situ Hybridization (FISH) with rRNA-targeted oligonucleotide probes. In: Paul JH (ed) Marine microbiology. Academic Press, London, p 207-226

Pomeroy LR (1974) The ocean's food web, a changing paradigm. Bioscience 24:499-504

Porter KG, Feig YS (1980) The use of DAPI for identifying and counting aquatic microflora. Limnol Oceanogr 25: 943-948

Proctor LM, Fuhrman JA (1990) Viral mortality of marine bacteria and cyanobacteria. Nature 343:60-62

Rappé MS, Connon SA, Vergin KL, Giovannoni SJ (2002) Cultivation of the ubiquitous SAR11 marine bacterioplankton clade. Nature 418:630-633

Sherr EB, Sherr BF (2002) Significance of predation by protists in aquatic microbial food webs. Antonie Leeuwenhoek 81:293-308

Sherr EB, Sherr BF, Fessenden L (1997) Heterotrophic protists in the Central Arctic Ocean. Deep-Sea Res II 44:1665-1682

Stoeck T, Hayward B, Taylor GT, Valera R, Epstein SS (2006) A multiple PCR-primer approach to access the microeukaryotic diversity in environmental samples. Protist 157: $31-43$

von Wintzingerode F, Göbel UB, Stackebrandt E (1997) Determination of microbial diversity in environmental samples: pitfalls of PCR-based rRNA analysis. FEMS Microbiol Rev 21:213-229

Vørs N, Buck KR, Chavez FP, Eikrem W, Hansen LE, Østergaard JB, Thomsen HA (1995) Nanoplankton of the equatorial Pacific with emphasis on the heterotrophic protists. Deep-Sea Res II 42:585-602

Wikner J, Hagström Å (1988) Evidence for a tightly coupled nanoplanktonic predator-prey link regulating the bacterivores in the marine environment. Mar Ecol Prog Ser 50: 137-145

Zhu F, Massana R, Not F, Marie D, Vaulot D (2005) Mapping of picoeucaryotes in marine ecosystems with quantitative PCR of the 18S rRNA gene. FEMS Microbiol Ecol 52:79-92 